\title{
MATICES DE LA LEGITIMACIÓN, EL AGRAVIO Y EL INTERÉS DEL ESTADO POR SU RESPONSABILIDAD INTERNACIONAL EN MATERIA DE DERECHOS HUMANOS*
}

(ALGUNAS CONSIDERACIONES SOBRE EL CASO «FELICETTI»)

\author{
POR \\ MARÍA ANGÉLICA GELLI \\ Profesora de Derecho Constitucional. \\ Universidad de Buenos Aires.
}

\section{LOS DEBERES DEL ESTADO EN MATERIA DE COMPROMISOS INTERNACIONALES. EL VALOR DE LA JURISPRUDENCIA INTERNACIONAL EN LA DOCTRINA DE LA CORTE SUPREMA}

Cuando el Estado argentino -al celebrar convenios, tratados, concordatos o emitir declaraciones - se obliga con otros Estados o con organismos internacionales, asume, en primer lugar, compromisos internacionales. En segundo término - dependiendo del tipo de convención y, sobre todo, si son Tratados de Derechos Humanos- contrae deberes internos frente a los titulares de los derechos acordados por el convenio de que se trate. Así pues, la responsabilidad estatal por incumplimiento de deberes emergentes de un tratado tiene una doble dimensión, externa e interna. En el caso específico de las convenciones

* Una primera versión de este artículo se publicó en El Derecho, Suplemento de Derecho Constitucional, Buenos Aires, 17 de abril de 2001. 
sobre derechos humanos, la inobservancia estatal en perjuicio de los habitantes puede tomar la forma de un acto positivo u omisivo en el aseguramiento de esos derechos.

La Corte Suprema tuvo ocasión de examinar el alcance de las obligaciones estatales en materia de derechos humanos emergentes de una Convención ratificada por el país -entonces sin jerarquía constitucional- en el precedente "Ekmekdjián c/Sofovich». En el caso, el Tribunal hizo lugar, por primera vez, al derecho de rectificación o respuesta del actor reconocido en el art. 14 del Pacto de San José de Costa Rica, aun cuando no se había dictado la ley reglamentaria de esa disposición en el orden interno'. Sostuvo la Corte Suprema que "la violación de un tratado internacional puede suceder tanto por el establecimiento de normas internas que prescriban una conducta manifiestamente contraria, cuanto por la omisión de establecer disposiciones que hagan posible su cumplimiento. Ambas situaciones resultarían contradictorias con la previa ratificación internacional del tratado; dicho de otro modo, significarían el incumplimiento o repulsa del tratado, con las consecuencias perjudiciales que de ello pudieran derivarse»". Por ello "...cuando la Nación ratifica un tratado que firmó con otro Estado, se obliga internacionalmente a que sus órganos administrativos y jurisdiccionales lo apliquen a los supuestos que esa convención contemple, siempre que contenga descripciones lo suficientemente concretas de tales supuestos de hechos que hagan posible su aplicación inmediata» ${ }^{3}$.

1 «Ekmekdjián, Miguel Ángel c/Sofovich, Gerardo y otros»; Fallos 315:1492 (1992); La Ley 1992-C-543; El Derecho 148:354. En el caso se trataba de los dichos de un escritor expresados en un programa de televisión acerca de personas sagradas para la Religión Católica. La referencias a la Virgen María fueron especialmente ofensivas para los sentimientos religiosos del actor aunque, éste, no había sido mencionado, ni siquiera aludido indirectamente, en las expresiones del escritor. El Tribunal consideró operativo el derecho de rectificación o respuesta y creó una regla en virtud de la cual aquélla no procede en caso de opiniones políticas o electorales. Admitió, en cambio, una curiosa acción colectiva -en realidad acción de clase de la categoría católicos - a fin de reparar sentimientos religiosos heridos ante expresiones insolentes, irrespetuosas, descomedidas, sin duda ofensivas del espíritu religioso, o simplemente delicado, de cualquier persona. Aunque la operatividad declarada del derecho es correcta, las expresiones que motivaron la respuesta claramente no estaban incluidas entre las merecedoras de réplica pues no se referían al actor, o a su condición de católico, directa o indirectamente. Por ello, en el caso, el remedio de la rectificación o respuesta no era el pertinente.

2 Conf. consid. 16 de "Ekmekdjián, Miguel Ángel c/Sofovich, Gerardo y otros", Fallos 315:1492 (1992), Enfasis agregado.

3 Conf. consid. 20 de "Ekmekdjián, Miguel Ángel c/Sofovich, Gerardo y otros", Fallos 315:1492 (1992), Énfasis agregado. 
La obligación de los órganos que deben aplicar el tratado en el orden interno, llega hasta el deber de utilizar la jurisprudencia internacional -en el caso "Ekmekdjián c/Sofovich" se trataba de la Opinión Consultiva, N. ${ }^{\circ}$, emanada de la Corte Interamericana de Derechos Humanos- como guía de interpretación y a emplearla en sus decisiones ${ }^{4}$.

Como se advierte, de la doctrina de "Ekmekdjián c/Sofovich" surgen varias reglas acerca del alcance de las responsabilidades estatales en punto al cumplimiento de los términos de las convenciones sobre derechos humanos: a) que aquella responsabilidad puede emerger tanto por la sanción de normas que violen los derechos reconocidos en el tratado, como de la omisión de dictarlas para hacerlas eficaces; b) que todos los poderes del Estado -incluidos el poder administrador y el poder judicial- están obligados a poner en ejercicio los derechos reconocidos en las convenciones; c) ello, siempre que los términos de éstas contengan con claridad los supuestos de hecho que la hagan aplicable (con lo cual la Corte Suprema argentina admite la existencia de hipótesis programáticas); y, d) que para interpretar el alcance de los derechos reconocidos en los tratados debe recurrirse, como guía de interpretación, a la jurisprudencia internacional de la Corte Interamericana.

Ahora bien: más allá del valor moral de los dictámenes o recomendaciones de la Comisión Interamericana de Derechos Humanos o de las Opiniones Consultivas de la Corte Interamericana de Derechos Humanos y de las eventuales responsabilidades que en el orden externo puedan generarse para los Estados Parte por el incumplimiento de la Convención ¿qué significa que la jurisprudencia internacional debe emplearse como guía de interpretación del alcance de las convenciones? ¿Cuán obligatoria resulta -o debería resultar- esa jurisprudencia, en especial para los tribunales judiciales? ¿Todas las decisiones de los organismos internacionales revisten la misma jerarquía y, por ende, idéntico carácter obligacional? ¿Las decisiones emanadas de la Convención Interamericana tienen el mismo valor jurídico que las emitidas por la Corte Interamericana de Derechos Humanos?

Varios pronunciamientos de la Corte Suprema argentina han recurrido a aquellos pronunciamientos, otorgándoles dispar valor $\mathrm{y}$, al mismo tiempo, dando alcance a las garantías derivadas de la Convención Americana de Derechos Humanos, Ilamada Pacto de San José de Costa Rica. Veamos.

${ }^{4}$ Conf. consid. 21 de "Ekmekdjián, Miguel Ángel c/Sofovich, Gerardo y otros» Fallos 315:1492 (1992), Énfasis agregado. 
En el caso "Giroldi», en el que se alegaba el incumplimiento de la garantía de recurrir la sentencia ante juez o tribunal superior, asegurada por el art. $8 .^{\circ}$, inc. h. de la Convención Americana, la Corte Suprema reiteró la doctrina "Ekmekdjián c/Sofovích». El Tribunal sostuvo en "Giroldi", que "la jurisprudencia de la Corte Interamericana de Derechos Humanos debe servir de guía para la interpretación de los preceptos de la Convención ${ }^{5}$. Al mismo tiempo, al examinar la garantía mencionada la Corte Suprema afirmó que la exigencia de la doble instancia no quedaba satisfecha con la posibilidad de interponer recurso extraordinario federal, mudando, de esa manera, su propio precedente establecido en el fallo "Jáuregui» ${ }^{6}$. Aunque, en realidad, la Corte Suprema, al hacer mérito de la reforma legal que la autorizó a efectuar el rechazo discrecional de aquel recurso ${ }^{7}$, dijo que ya no era aplicable la doctrina de "Jáuregui" pues, habiendo mudado las reglas y excepciones de la competencia apelada del Tribunal, "el recurso extraordinario no constituía un remedio eficaz para la salvaguarda de la garantía de la doble instancia que debe observarse dentro del marco del proceso penal como garantía mínima para toda persona inculpada de delito» ${ }^{8}$. En consecuencia de ello, la Corte Suprema declaró la inconstitucionalidad del art. 459, inc. 2. ${ }^{\circ}$ del Código Procesal Penal de la Nación, en tanto la norma vedaba la admisibilidad del recurso de casación contra las sentencias de los tribunales en lo criminal en razón del monto de la pena ${ }^{9}$.

Más adelante, en "Bramajo", la Corte Suprema incluyó a las opiniones de la Convención Americana de Derechos Humanos entre los documentos que debían servirle de guía de interpretación de las dis-

5 Conf. consid. 11 de "Giroldi", Fallos 318:514(1995), La Ley 1995-D-461. El Derecho, 5 de julio de 1995.

6 "Jáuregui", Fallos 311:274 (1988). En este caso, la Corte Suprema sostuvo que el recurso extraordinario federal cumplimentaba del requisito de la doble instancia en materia penal, dispuesto por el Pacto de San José de Costa Rica. El Derecho 129-145. Con comentario de Bidart Campos, Germán J.: «El recurso extraordinario no satisface el requisito de la doble instancia que para el proceso penal prevén los pactos internacionales de derechos humanos". El autor criticó, en esa nota, la decisión de la Corte Suprema aduciendo que, de todas maneras, el recurso extraordinario federal es limitado en materia de revisión. El Derecho, 129-191.

7 El art. 280 del Código Procesal Civil y Comercial de la Nación autorizó a la Corte Suprema, según su sana discreción, a rechazar el recurso extraordinario por falta de agravio federal suficiente o cuando las cuestiones planteadas resultaren insustanciales o carentes de trascendencia.

8 Conf. consid. $7 .^{\circ}$ y $8 .^{\circ}$ de "Giroldi", Fallos 318:514 (1995).

9 Conf. consid. 10 de "Giroldi», Fallos 318:514 (1995). 
posiciones del mencionado Tratado $^{10}$. En el caso, fijó las pautas a las que se debía ajustar la interpretación de la ley 24.390, reglamentaria de art. $7 .^{\circ}$, ap. 5 de aquella Convención, en tanto esta norma reconocía el derecho a ser juzgado en un plazo razonable o, en su defecto, a ser dejado en libertad. La Corte Suprema, si bien rechazó la inconstitucionalidad del art. 1 de la ley 24.390, entendió que los plazos de esa norma no debían aplicarse de forma automática, por el mero transcurso del tiempo pues según el informe de la Comisión Americana, "el Estado Parte no está obligado a fijar un plazo válido para todos los casos, con independencia de sus circunstancias, quedando el concepto de plazo razonable sujeto a la apreciación de la gravedad de la infracción, en cuanto a los efectos de establecer si la detención ha dejado de ser razonable» ${ }^{11}$.

Sin embargo, pese a la decisión recaída en "Bramajo", en el caso "Acosta" —referido a la revisión de las decisiones judiciales firmes en el orden interno, como consecuencia de recomendaciones de la Comisión- la Corte Suprema emitió un pronunciamiento ambiguo.

En efecto, el Tribunal sostuvo que el Estado argentino debe realizar los mayores esfuerzos para cumplir las recomendaciones de la Comisión, pero que "la jurisprudencia internacional por más novedosa y pertinente que se repute no podría constituir un motivo de revisión de resoluciones judiciales firmes ${ }^{12}$. Aun cuando la Corte Suprema citó su

10 Conf. consid. 8. ${ }^{\circ}$ de "Bramajo», Fallos 319:1840 (1996), La Ley 1996-E-409. Con nota de Posse, Francisco Javier, "La doctrina de la equidad en un fallo trascendental de la Corte".

11 Conf. consid. 12 de "Bramajo», Fallos 319:1840 (1996). Como se ha señalado con acierto, existen diferencias entre la aplicación de límites objetivos a la detención preventiva -típicamente plazos máximos- y las fórmulas genéricas y abstractas para conceder o denegar la libertad, por falta de sentencia condenatoria Conf. Albanese, Susana, "La prisión preventiva y el plazo razonable", La Ley. Suplemento de Derecho Constitucional, 5 de diciembre de 1997. En mi opinión no constituyen formas genéricas las que toman en consideración la complejidad del caso, la conducta del inculpado y la diligencia de la autoridad competente (Conf. Comisión Americana de Derechos Humanos, citada por Susana Albanese) y, por lo tanto, pueden aplicarse para mensurar el plazo razonable de detención. Debe señalarse que en muchas ocasiones la complejidad del caso puede estar relacionada con la gravedad del delito imputado en cuyo caso este elemento también debe tenerse en cuenta para aplicar la garantía.

12 Conf. consid. 13 de "Acosta, Claudia Beatriz», Fallos 321:3555 (1998), Jurisprudencia Argentina, junio 30 de 1999. Con notas de Bidart Campos, Germán J. y Albanese, Susana, "El valor de las recomendaciones de la Comisión Interamericana de Derechos Humanos»; y Sagüés, Néstor Pedro, "Nuevamente sobre el valor, para los jueces argentinos, de los pronunciamientos de la Corte Interamericana y de la Co- 
propio precedente en "Giroldi», el Tribunal no aclaró si se refería a la jurisprudencia de la Corte Interamericana, a la de la Convención, o a ambas a la vez. De todos modos, las afirmaciones de la Corte Suprema sobre el valor de los pronunciamientos referidos, lo fueron en obiter dicta, ya que al rechazar la posibilidad de revisar la sentencia firme, sostuvo la falta de relación directa entre las recomendaciones de la Comisión y la privación de libertad que se encontraban cumpliendo los condenados en virtud de una sentencia con valor de cosa juzgada ${ }^{13}$.

\section{EL CASO «FELICETTI»Y SU CIRCUNSTANCIA}

El 23 de enero de 1989, después de más de un lustro de restaurada la democracia constitucional en la República Argentina, un grupo civil armado perteneciente al Movimiento Todos por la Patria, atacó una unidad del Ejército en la localidad de La Tablada.

El hecho produjo conmoción en la opinión pública por su secuela de muerte y destrucción; porque había sucedido durante la administración de un gobierno surgido de elecciones populares y libres - sin proscripciones de ninguna especie-, y porque aparecía como un retorno no querido por la sociedad a las luchas armadas de los años setenta, considerada por algunos de los protagonistas de entonces, como una verdadera guerra ${ }^{14}$.

Retomar el cuartel llevó al Ejército y a las fuerzas policiales de la Provincia de Buenos Aires más de treinta y seis horas; al cabo de ese tiempo, se detuvo a varios de los atacantes del regimiento, pero el

misión Interamericana de Derechos Humanos en materia de interpretación de Derechos Humanos". En el caso "Acosta", los defensores de éstas y otras personas, condenadas por los sucesos de La Tablada, presentaron un habeas corpus con sustento en la recomendación formulada por la Comisión Interamericana de Derechos Humanos al Estado argentino, a fin de que éste reparase a las víctimas de la represión a los asaltantes del cuartel. Los demandantes interpretaron que la primera reparación que se les debía era la libertad. Como podrá advertirse, "Acosta" implicó una estrategia judicial frustrada y anterior a "Felicetti".

13 Conf. consid. 13 de "Acosta", Fallos 321:3555 (1998).

${ }^{14}$ La mayoría de los militares argentinos se refirieron a los trágicos episodios de los años setenta caracterizándolos de guerra sucia, con la finalidad imposible de justificar las violaciones a los derechos humanos que se infligieron desde el poder estatal. Curiosamente, desde otra perspectiva Bonasso sostiene que en aquel período de la historia nacional se vivió una guerra. Conf. Bonasso, Miguel, Diario de un clandestino, Planeta. Espejo de Argentina. Buenos Aires, noviembre de 2000, págs. $249,2 .^{\circ}$ párrafo; $258,2 .^{\circ}$ párrafo; $260,3 .^{\circ}$ párrafo; $281,2 .^{\circ}$ párrafo. 
jefe que comandó la operación y su esposa lograron huir. Diez meses más tarde se juzgó a los detenidos por violación de la ley de defensa de la democracia en juicio oral y público que, además, fue rápido en virtud de las modificaciones procesales sancionadas con anterioridad. Sin embargo, aquella norma establecía la instancia única a cargo de la Cámara Federal de Apelaciones, lo que impedía la eventual revisión de las sentencias. La carencia de apelación dispuesta en la ley, entraba en contradicción clara con lo dispuesto en el citado art. $8 .^{\circ}$, inc. h) del Pacto de San José de Costa Rica, vigente en la República Argentina desde 1984, cuyas cláusulas aseguran el derecho a la revisión judicial en materia penal ${ }^{15}$. No obstante, cuando los finalmente condenados por los sucesos de La Tablada apelaron a la Corte Suprema, no invocaron la violación del derecho a la doble instancia en materia penal. El Tribunal rechazó el recurso intentado en 1992 y la sentencia quedó firme ${ }^{16}$.

A partir de entonces se sucedieron una serie de incidencias judiciales promovidas por los condenados en el orden interno y varias presentaciones en la que peticionaron a la Comisión Americana de Derechos Humanos, denunciando lo que estimaban una violación de los términos y derechos reconocidos por aquel Tratado ${ }^{17}$. A su turno, la Comisión entendió que no había evidencia de la violación a la libertad personal de los presentantes, pero sí estimó vulnerados, entre otros derechos, el de recurrir del fallo condenatorio y el de obtener un recurso sencillo y efectivo contra aquél. En consecuencia recomendó al Estado argentino que adoptase las medidas más apropiadas para reparar a las víctimas y a sus familiares el daño sufrido ${ }^{18}$.

El alcance de la recomendación emitida por la Comisión Interamericana de Derechos Humanos no fue precisado por ésta, lo que motivó un pedido de habeas corpus, - solicitando la libertad de los condenados por los sucesos de La Tablada- cuyo recurso extraordinario fue rechazado por la Corte Suprema en el ya citado precedente "Acosta»" ${ }^{19}$.

${ }^{15}$ La Convención Americana de Derechos Humanos fue firmada el 22 de noviembre de 1969. Aprobada por la República Argentina mediante la ley 23.054 (B. O. 27-3-84) y ratificada el 14 de agosto de 1984, con reservas y declaraciones interpretativas.

${ }^{16}$ Conf. Fallos 315:319.

17 Conforme al art. 44 del Pacto de San José de Costa Rica, "cualquier persona o grupo de personas, o entidad no gubernamental legalmente reconocida en uno o más Estados miembros de la Organización, puede presentar a la Comisión peticiones que contengan denuncias o quejas de violación de esta Convención por un Estado Parte».

18 Conf. Informe 55/97 de la Comisión Interamericana de Derechos Humanos.

19 Acosta» Fallos 321:3555 (1998). Ver nota 12 y 13. 
Una nueva presentación, esta vez articulando un recurso de revisión de la sentencia condenatoria emanada de la Cámara Federal de San Martín, fue desestimada por este tribunal y, en su momento, también rechazada la apelación por parte de la Cámara Nacional de Casación Penal. En esta ocasión, los agraviados consintieron el fallo de la Casación.

Así las cosas, en tanto varios de los condenados cumplían con un prolongado ayuno de protesta - las alternativas acerca de lo que el Estado haría con ellos ocupaba la atención pública y generaba encendidas polémicas - la cuestión tomó una curiosa vuelta jurídica.

En efecto, el Poder Ejecutivo - después de agotar las propuestas para que el Poder Legislativo creara por ley el recurso de apelación pertinente- dedujo, por intermedio del Procurador del Tesoro, recurso extraordinario federal contra la decisión de la Cámara de Casación Penal que denegó la revisión de las sentencias firmes ${ }^{20}$. Declarado inadmisible este recurso, el Poder Ejecutivo interpuso queja ante la Corte Suprema.

\section{LA LEGITIMIDAD Y EL INTERÉS INVOCADOS POR EL PODER EJECUTIVO}

El Procurador del Tesoro, en representación del Poder Ejecutivo, sostuvo que el Estado Nacional estaba legitimado para recurrir en el caso "Felicetti», en razón del interés institucional que tenía en el cumplimiento de la Convención Americana de Derechos Humanos y en la ejecución de la recomendación emanada de la Convención Interamericana, a fin de evitar, por todos los medios a su alcance, el descrédito internacional o, eventualmente, la imposición de sanciones que pudieran derivarse del indicado y eventual incumplimiento ${ }^{21}$.

Con invocación de la jerarquía constitucional de aquella Convención, reconocida en el art. 75, inc. 22 de la Constitución Nacional, y de los deberes que como Jefe del Estado tiene el Presidente de la Nación, estimó que la denegación del recurso de revisión de la sentencia recaída en autos, podría generar lesión, de modo cierto y directo en el Estado Nacional.

20 No obstante, se ha sostenido que hasta tanto no se conceda la revisión de la sentencia, garantizada por la Convención Americana, no cabe sostener, con propiedad, que existe sentencia firme. Conf. Bidart Campos, Germán, "La exigencia constitucional e internacional de la alzada en el proceso penal», La Ley, Suplemento de Derecho Constitucional, 12 de marzo de 2001.

21 "Felicetti, Roberto y otros s/revisión», C. S. F. 787. XXXVI (2000). 
Así, el Presidente, jefe supremo del Estado (art. 99, inc. 10 de la C. N.), atribuido para celebrar tratados y mantener buenas relaciones con los organismos internacionales y las naciones extranjeras (art. 99, inc. 11 de la C. N.) tendría el deber constitucional de ocurrir ante el Poder Judicial a fin de obtener otras medidas, enderezadas a evitar aquella responsabilidad internacional, con mucha mayor razón ante la inactividad legislativa. En esa dirección, el Procurador del Tesoro afirmó no representar los intereses de los condenados, ni los del Ministerio Público, sino los intereses específicos y concretos del Estado Nacional. Finalmente, examinando los alcances de la sentencia denegatoria de la revisión judicial que motivó la queja, el representante del Presidente de la Nación sostuvo que ese fallo excedía los términos de la causa penal pues agraviaba el interés jurídicamente protegido del Estado Nacional, en su calidad de estado parte de la Convención ${ }^{22}$.

Como puede advertirse, el Poder Ejecutivo fundó su legitimidad en la ampliación de sus deberes y responsabilidades internacionales ante los incumplimientos de los otros poderes del Estado que estaba señalando: el Poder Legislativo que no proporcionó la norma procesal adecuada para hacer viable la revisión, y el Poder Judicial que desestimó el recurso.

\section{LOS DEBERES Y RESPONSABILIDAD DEL ESTADO EN MATERIA DE DERECHOS HUMANOS, LA JURISPRUDENCIA INTERNACIONAL Y LA DOCTRINA DE LA CORTE SUPREMA EN EL CASO «FELICETTI»}

En el dictamen del Procurador General —valorado técnicamente aun por una de las disidencias ${ }^{23}$ - se enumeraron los obstáculos de procedencia de la queja, todos ellos dirigidos a negar la legitimidad del Estado: a) la promoción y ejercicio de la acción penal corresponde al Ministerio Público, órgano independiente en virtud de lo establecido por el art. 120 de la Constitución Nacional; b) la responsabilidad alegada por el Estado es conjetural; c) el proceso recursivo, en autos, está concluido, pues las partes comenzaron aquella vía y la interrumpieron, consintiéndola; d) la intromisión del Procurador del Tesoro en la causa, desarticula la división de poderes; e) la presentación de aquél afecta el

${ }^{22}$ Conf. los agravios enumerados en el p. II del dictamen del Procurador General «Felicetti, Roberto y otros s/revisión», C.S. F.787. XXXVI (2000).

${ }^{23}$ Conf. consid. $5 .^{\circ}$ de la disidencia del ministro Petracchi en «Felicetti, Roberto y otros s/revisión", C.S. F. 787. XXXVI (2000). 
principio del juez natural y la independencia del Poder Judicial; f) la reconocida jefatura internacional del Estado dota al Presidente de otros instrumentos para implementarla, que no consisten en el ejercicio de la acción penal, en una causa fenecida ${ }^{24}$.

Por su parte, el voto mayoritario de la Corte Suprema -compartiendo el dictamen del Procurador General- rechazó la queja del Estado por considerar que éste no era parte en el caso y, por ende, no tenía legitimidad ${ }^{25}$. Con ello, el Tribunal comprimió los deberes del Poder Ejecutivo en materia de responsabilidad internacional por el cumplimiento de Tratados de Derechos Humanos y lo eximió de la carga de obtener judicialmente para los condenados, la revisión de la sentencia. Pero, al seguir el dictamen del Procurador General, hizo suya la aseveración de éste en el sentido de que la jefatura internacional del Estado dota al Presidente de otros instrumentos para implementarla.

No obstante el rechazo de la queja por estimar ausente la legitimidad del Estado, La Corte Suprema, en obiter dicta, se pronunció sobre la cuestión sustantiva. Para ello examinó el alcance de las recomendaciones de la Comisión Americana emitidas en el Informe 55/97, enfatizando que en ésta se instó al Estado argentino a adoptar las medidas necesarias con arreglo a sus procedimientos constitucionales a fin de hacer plenamente efectiva, en lo sucesivo, la garantía judicial del derecho a la apelación de las personas procesadas bajo la ley 23.077.

Por otro lado, con cita del precedente "Acosta", la Corte Suprema reiteró su doctrina acerca de que si bien la jurisprudencia de los tribunales internacionales deben servir de guía de interpretación de los preceptos convencionales, ello no equivale a consagrar como deber de los jueces el dar cumplimiento a su contenido, al no tratarse de decisiones vinculantes para el Poder Judicial ni constituir motivo de revisión de resoluciones judiciales firmes ${ }^{26}$.

Ahora bien, en lo que en mi opinión constituye el núcleo de la cuestión sustantiva examinada por la Corte Suprema en obiter dictum, el Tribunal dio alcance interpretativo al art. $8 .^{\circ}$, inc. h) de la Convención Americana. En tal sentido, sostuvo que esa norma no impone necesariamente la renovación del debate realizado en el proceso, pues el derecho a recurrir del fallo ante un juez o tribunal superior no descalifica

${ }^{24}$ Énfasis agregado.

${ }^{25}$ Votaron por la mayoría los ministros Nazareno; Moliné O’Connor; Belluscio; López y Vázquez.

${ }^{26}$ Conf. consid. 6 y 9 del voto de la mayoría en «Felicetti, Roberto y otros s/revisión", C.S. F. 787. XXXVI (2000) Énfasis agregado. 
la instancia única sino que impone que la sentencia provenga del tribunal superior en la escala jerárquica. Si ello no fuese así, sigue diciendo la Corte Suprema, se pondría en pugna la cláusula del pacto con el art. 117 de la Constitución Nacional, en tanto esta norma establece la competencia originaria y exclusiva de la Corte Suprema de Justicia de la Nación, también en materia penal, para las hipótesis allí señaladas ${ }^{27}$.

Aunque el argumento es razonable, no cabe duda de que al utilizarlo, la Corte Suprema está creando dos reglas, una de ellas restrictiva en grado sumo para el alcance de la garantía de la doble instancia en materia penal. Por la primera de ellas, la garantía se satisface aun sin revisión por parte de otro tribunal, bastando con que quien emita la sentencia sea el superior en la organización jerárquica respectiva. En consecuencia de ello, si los lindes de la garantía de la revisión judicial de sentencias en materia penal son tan estrechos, la responsabilidad de los órganos de poder del Estado parte se comprime en la misma medida. Tal parece señalarlo la Corte Suprema al afirmar que a la luz de lo que considera circunstancias objetivas, el Estado argentino no incurrirá en responsabilidad internacional por la actuación del Poder Judicial ${ }^{28}$. Y ello, según la Corte Suprema, sin que obste a que el Poder Legislativo sancione en el futuro el remedio procesal en cuestión y más allá del legítimo propósito del Poder Ejecutivo al considerar razonable y apropiado - para preservar la responsabilidad estatal- recurrir a la vía judicial que intentó sin éxito ${ }^{29}$.

Como se advierte, la Corte Suprema se asume a sí mima como intérprete final de la Constitución en la delimitación de las respectivas responsabilidades de los otros poderes del Estado, en materia de responsabilidad internacional por el cumplimiento de las Convenciones sobre Derechos Humanos; los exonera, en el caso particular, de cualquier otro deber y expresa deferencia para lo obrado por el Presidente de la Nación.

Por fin, en la segunda regla creada en "Felicetti» y no la menos importante, el Tribunal reserva para sí la interpretación de las cláusulas de la Convención filtrando, de tal manera, la hermenéutica que realicen a su turno la Comisión o la Corte Interamericana de aquel tratado.

${ }_{27}$ Conf. consid. 10 del voto de la mayoría en «Felicetti, Roberto y otros s/revisión» C.S. F. 787. XXXVI (2000), Énfasis agregado.

${ }^{28}$ Conf. consid. 12 del voto de la mayoría en «Felicetti, Roberto y otros s/revisión", C.S. F. 787. XXXVI (2000), Énfasis agregado.

${ }^{29}$ Conf. consid. 12 y 16, respectivamente, del voto de la mayoría en «Felicetti, Roberto y otros s/revisión», C.S. F. 787. XXXVI (2000), Énfasis agregado. 


\section{LOS MATICES DE LA LEGITIMACIÓN, LOS DEBERES Y LAS RESPONSABILIDADES ESTATALES, EN LAS DISIDENCIAS DEL CASO «FELICETTI»}

Al contrario de lo dictaminado por el Procurador General y de lo resuelto por la mayoría de la Corte Suprema, las cuatro disidencias reconocieron la legitimidad del Estado Nacional para recurrir por vía extraordinaria, demandando la revisión judicial de sentencias condenatorias.

Para el ministro Fayt, el interés del Estado no se identifica ni sustituye al de las partes. La atribución-deber del Poder Ejecutivo, con base en el art. 99, inc. 11, le obliga a no permanecer impasible frente a la situación de irregularidad del ordenamiento jurídico, en tanto éste no proporciona la alternativa de la doble instancia en materia penal, violando con ello la garantía reconocida por la Convención Americana con carácter operativo ${ }^{30}$. Por su parte, y de acuerdo con la doctrina de este voto, el Poder Judicial — del modo en que creó pretorianamente el amparo- estaría impelido por sus deberes en materia de responsabilidad internacional, a agregar un supuesto más de revisión judicial a los establecidos en el art. 479 del Código Procesal de la Nación ${ }^{31}$.

Aun señalando las carencias en la legitimación del Estado - diríamos que éste tiene una legitimidad débil para el ministro Petracchi- en opinión del magistrado, aquellas flaquezas deben ceder a fin de evitar la privación de justicia por trabas formales ${ }^{32}$.

Con un énfasis mayor en el reconocimiento de la legitimidad del Estado Nacional en el caso, el ministro Boggiano afirmó el interés propio, actual y concreto de aquél en prevenir la eventual responsabilidad de orden patrimonial, conforme las prescripciones de los arts. 63.1 y 68 de la Convención Americana de Derechos Humanos ${ }^{33}$. De acuerdo con el magistrado, los deberes del Estado van en la dirección de remover los obstáculos para el goce de los derechos bajo la Convención, e involucran y obligan por igual a los tres órganos de poder ${ }^{34}$. No obstante, el

${ }^{30}$ Conf. consid. $5 .^{\circ}$ del voto en disidencia del ministro Fayt en «Felicetti, Roberto y otros s/revisión», C. S. F. 787. XXXVI (2000), Énfasis agregado.

${ }^{31}$ Conf. consid. 10 del voto en disidencia del ministro Fayt en "Felicetti, Roberto y otros s/revisión» C.S. F. 787. XXXVI (2000), Énfasis agregado.

${ }^{32}$ Conf. consid. $5 .^{\circ}$ del voto en disidencia del ministro Petracchi en «Felicetti, Roberto y otros s/revisión", C.S. F. 787. XXXVI (2000), Énfasis agregado.

${ }_{33} \mathrm{El}$ art. 63. 1 de la Convención Americana dispone: Cuando decida que hubo violación.

${ }^{34}$ Conf. consid. 72 del voto en disidencia del ministro Boggiano en «Felicetti, Roberto y otros s/revisión", C.S. F 787 XXXVI (2000). 
ministro reitera la doctrina de la Corte Suprema en el sentido de que la jurisprudencia internacional debe servir como guía de interpretación de la Convención; pero, por otro lado, y en lo que considero una crítica a las recomendaciones de la Comisión Americana, relativiza el valor de éstas que lucen en el ya mencionado Informe 55/ 97 pues, en su opinión, aquélla, al instar al Estado argentino a "hacer plenamente efectiva, en lo sucesivo, la garantía judicial de la doble instancia», establece una ilegítima restricción de la garantía establecida en el art. $8^{\circ}$, inc. h) de la Convención ${ }^{35}$.

Así pues, el voto del ministro Boggiano se une a la mayoría, en punto a reivindicar para la Corte argentina el derecho a interpretar las cláusulas de la Convención por sobre la Jurisprudencia emanada de sus dos órganos, la Comisión y la Corte Interamericana.

En el marco de las atribuciones ejecutivas derivadas del art. 99, inc. 11 de la Constitución Nacional, el ministro Bossert, reconoce la legitimidad del Estado argentino en el caso "Felicetti» en virtud del compromiso asumido por aquél de respetar la legalidad internacional ${ }^{36}$.

\section{EL PESO INSTITUCIONAL DE LA DOCTRINA DE LA CORTE SUPREMA Y LAS POLÍTICAS A OUE SE CREYÓ OBLIGADO EL PODER EJECUTIVO. LA CONMUTACIÓN DE PENAS}

Las cuestiones debatidas en el caso "Felicetti», de arduo y largo trámite, no concluyeron con la sentencia emitida por la Corte Suprema.

En efecto, pese a que la doctrina de la Corte Suprema libraba al Poder Ejecutivo de otras responsabilidades en el orden interno y le aseguraban una interpretación de las obligaciones internacionales emanadas de la Convención por parte del máximo Tribunal del país, el Presidente todavía se creyó obligado a adoptar otras medidas para cumplir con las recomendaciones de la Comisión Interamericana. Así, en uso de atribuciones enunciadas en el art. 99, inc. 5 de la Constitución Nacional, emitió el decreto 1263/2000 por el que conmutó por otras menores, las penas privativas de libertad impuestas a los condenados por los sucesos de La Tablada ${ }^{37}$.

${ }^{35}$ Conf. consid. 20 del voto en disidencia del ministro Boggiano en «Felicetti, Roberto y otros s/revisión" C.S. F 787 XXXVI (2000).

${ }^{36}$ Conf. consid. 52 del voto en disidencia del ministro Bossert en «Felicetti, Roberto y otros s/revisión" C.S. F 787 XXXVI (2000).

37 Decreto $1263 / 2000$ (B. O. 3-12001). 
El Presidente de la Nación hizo mérito de la comunicación que le enviara la Comisión Interamericana, en la que ésta valoró sus esfuerzos para cumplir con las recomendaciones de la Convención, acciones emprendidas por el Poder Ejecutivo que fracasaron ante el Poder Legislativo y el Poder Judicial.

Salvo el Poder Legislativo, que omitió pronunciarse porque no sancionó ninguna ley que pudiera aplicarse al caso, asegurando la doble instancia, los otros Poderes articularon sendas respuestas; cada uno de ellos, a su vez, interpretó sus obligaciones internacionales conforme a los términos del Pacto de San José de Costa Rica y obró en consecuencia.

Más allá de la conveniencia o equidad con que se resolvió el problema $^{38}$, lo notable del caso $-y$ de una de sus posibles lecturas, en especial- es que aun discrepando acerca de los alcances de la responsabilidad estatal en materia de cumplimiento de las obligaciones internacionales, la cuestión atravesó distintos carriles institucionales dentro de las alternativas del sistema político -lo que fortalece las instituciones- pero con una inquietante disparidad de criterios en un tema de alta sensibilidad.

38 Uno de los militares que participó en las acciones de recuperación del regimiento tomado por los guerrilleros, el oficial del Ejército Nanni, herido y condecorado por su actuación en los episodios, devolvió al Poder Ejecutivo, en señal de protesta, la medalla obtenida. 